\title{
FOSS4G AS A KEY BUILDING BLOCK FOR CASE-BASED LEARNING IN GEOGRAPHIC INFORMATION EDUCATION
}

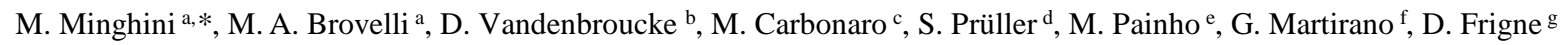 \\ ${ }^{a}$ Department of Civil and Environmental Engineering, Politecnico di Milano, Piazza Leonardo da Vinci 32, 20133 Milano, Italy - \\ (marco.minghini, maria.brovelli)@polimi.it \\ ${ }^{\mathrm{b}}$ KU Leuven, Spatial Applications Division Leuven (SADL), Oude Markt 13, 3000 Leuven, Belgium - \\ danny.vandenbroucke@kuleuven.be \\ ${ }^{c}$ GISIG - Geographical Information Systems International Group, Via Piacenza 54, 16138 Genova, Italy - m.carbonaro@ gisig.it \\ d Paris Lodron University Salzburg, Department of Geoinformatics - Z_GIS, Hellbrunnerstraße 34, 5020 Salzburg, Austria - \\ stefan.prueller@sbg.ac.at \\ e Nova IMS - Nova Information Management School, Universidade Nova de Lisboa, 1070-312 Lisboa, Portugal - \\ painho@novaims.unl.pt \\ ${ }^{\mathrm{f}}$ Epsilon Italia, Via Pasquali 79, 87040 Mendicino (CS), Italy - g.martirano@epsilon-italia.it \\ g Geosparc nv, Brugsesteenweg 587, 9030 Ghent, Belgium - dirk.frigne@geosparc.com
}

\section{Commission IV, WG IV/4}

KEY WORDS: Academia, Cased-based Learning, Enterprise, Co-creation of Knowledge, Collaboration, Education, FOSS4G, Geographic Information

\begin{abstract}
:
In the sector of Geographic Information (GI) there is a gap between the education and training currently being offered by European universities and the knowledge and skills required by enterprises and public authorities. New forms of collaboration based on innovative methods are needed to cope with the challenges derived from the fast technological developments in the geospatial and ICT field. This paper presents the approach and the first findings of the EU Erasmus+ project giCASES - Creating a UniversityEnterprise Alliance for a Spatially Enabled Society (2016-2018) which addresses this challenge by introducing new methods for case-based and collaborative learning, and for the co-creation, management and sharing of knowledge between universities and enterprises. The aim of the project is to develop new training material and create innovative, multi-disciplinary learning processes based on real-world case studies (case-based learning). The paper focuses on the methodological approach developed during the first half of the project, and presents the 6 case studies where this approach will be tested during the second half. Despite the diversity of application domains (indoor mapping, environmental hazards, e-Government, utility networks, energy saving policies, and forestry), the case studies are all relevant to open source software and FOSS4G technologies will play a key role in their implementation, thus demonstrating their matureness and flexibility not only as GI teaching tools at the universities, but also as powerful means to develop innovative new services at the companies.
\end{abstract}

\section{INTRODUCTION}

Citizens need an increasingly large set of competences to flexibly adapt to a rapidly changing and highly interconnected world with emerging societal challenges, where competences can be defined as the combination of knowledge, skills and attitudes appropriate to the context (European Commission, 2007). Knowledge is defined as the outcome of the assimilation of information through learning; skills indicate the ability to apply knowledge and use know-how to complete tasks and solve problems; and competence means the proven ability to use knowledge, skills and personal, social and/or methodological abilities, in work or study situations and in professional and personal development (European Commission, 2008). In the Geographic Information (GI) sector, there is a recognized gap between the knowledge and skills currently being offered by European universities and those needed by organizations such as enterprises and public authorities where the GI projects take place (Rip et al., 2014). Among the reasons pointed out for this mismatch are the fast technological development as well as the recent societal changes in the geospatial domain such as the EU INSPIRE Directive and the e-government actions of the member states (Vandenbroucke et al., 2014).

giCASES - Creating a University-Enterprise Alliance for a Spatially Enabled Society (http://www.gicases.eu) is a Knowledge Alliance project, co-funded by the Erasmus+ programme of the European Commission with the aim of developing innovative methods for the co-creation, management and sharing of knowledge between universities and enterprises/ governments. Co-creation of knowledge is defined as the cooperative and multi-directional process through which two or more subjects interact with each other in a collaborative fashion to generate new knowledge, skills and competences, so that the outcome is for each subject more profitable from what a single or the non-totality of the subjects would achieve (Minghini and Brovelli, 2017).

\footnotetext{
* Corresponding author
} 
The concept of co-creation is also linked with the history of open source software. While, in the early days of computer programming, software was machine-dependent and was supplied by the computer hardware suppliers who used it as a unique selling proposition to promote their hardware architecture, later on software became more and more hardwareindependent and the largest hardware vendors decided not to provide the source code of the operating system anymore. It was this event that triggered Richard Stallman, amongst others, to start writing collaborative software for these machines, and sharing it for reuse (Wikipedia, 2017). Since then more and more people are collaboratively writing and creating software architectures and solutions for the benefit of the public domain. giCASES wants to incorporate the lessons learned from these communities to secure the experience in its results. The project consortium is formed by a well-balanced set of universities, enterprises and public authorities, some of which play a leading role in the Open Source Geospatial Foundation (OSGeo, http://www.osgeo.org).

Collaboration between universities and enterprises currently happens in a rather traditional manner, i.e. through guest courses, $\mathrm{MSc} / \mathrm{PhD}$ thesis, internships, etc. (Vancauwenberghe and Vandenbroucke, 2016). This poses several difficulties in overpassing the boundaries of both practitioners and academics with respect to disciplines and languages. This difficulty limits the potential to innovate and may at the same time create tensions when cooperation is required, and finally can undermine long-term results. For solving such difficulties, a common framework among all involved actors has to be created, including the enterprises, students and the academic staff. The approach is based on the assumption that complex topics need a practical involvement to be understood, acquired and finally used by all stakeholders involved. Thus, the main objective of the project is to boost the innovation by promoting a joint development and implementation of new teaching and learning methods based on case-based learning. More specifically, in giCASES co-creation of knowledge takes place throughout the development of 6 case studies (CSs) in different application areas, where real-world cases are used to illustrate and deepen the knowledge about how different solutions can be applied and used. The whole project, that will lead to the establishment of a European-wide University-Enterprise Alliance, is developed under the spirit of open source and open access so that its output can be easily spread.

The remainder of the paper is organized as follows. Section 2 offers an overview of the methodology foreseen within the giCASES project and presents in more detail the tasks which have been performed so far. These include a need analysis and state of art, the specification of the processes and tools required for co-creation of knowledge, and the specifications of the collaboration platform to be used in the project. Section 3 presents the $6 \mathrm{CSs}$ which, based on the established methodology and widely exploiting open source software, will be practically implemented over the second half of the project duration. Section 4 concludes the paper by providing an outlook on the future development of the project and a more general discussion on the importance of openness in the GI domain.

\section{METHODOLOGY}

The overall giCASES methodology is depicted in Figure 1 together with the Work Packages (WPs) in which the project is organized. First, a study on the State-of-the-Art is performed to assess the way higher education institutions (HEIs) and public or private sector companies currently collaborate in the context of geospatial education and training. In this preparatory study, requirements and expectations as well as examples of best practices are analysed as well. The second stage consists in the development of a consistent approach for case-based learning studies, and the definition of specifications for a collaborative learning platform to support the CSs. Finally, the CSs are implemented by preparing the necessary learning materials, making the platform operational and conducting the CSs during a series of training actions. The two first stages have been already carried out and are described in further detail in this section.

The main outputs and outcomes of the project are its knowledge-based assets, the co-creation processes and the new learning materials, as well as the collaboration platform and the CSs in different application domains. It is important to notice that the development of the CSs is led by the giCASES industry partners, in close collaboration with the university partners. The details of such processes are depending on the detailed requirements of the partners, which in turn define the required functionalities of the collaboration platform. The strategic business perspective is based on a Knowledge Management (KM) Process Framework by Bukowitz and Williams (1999).

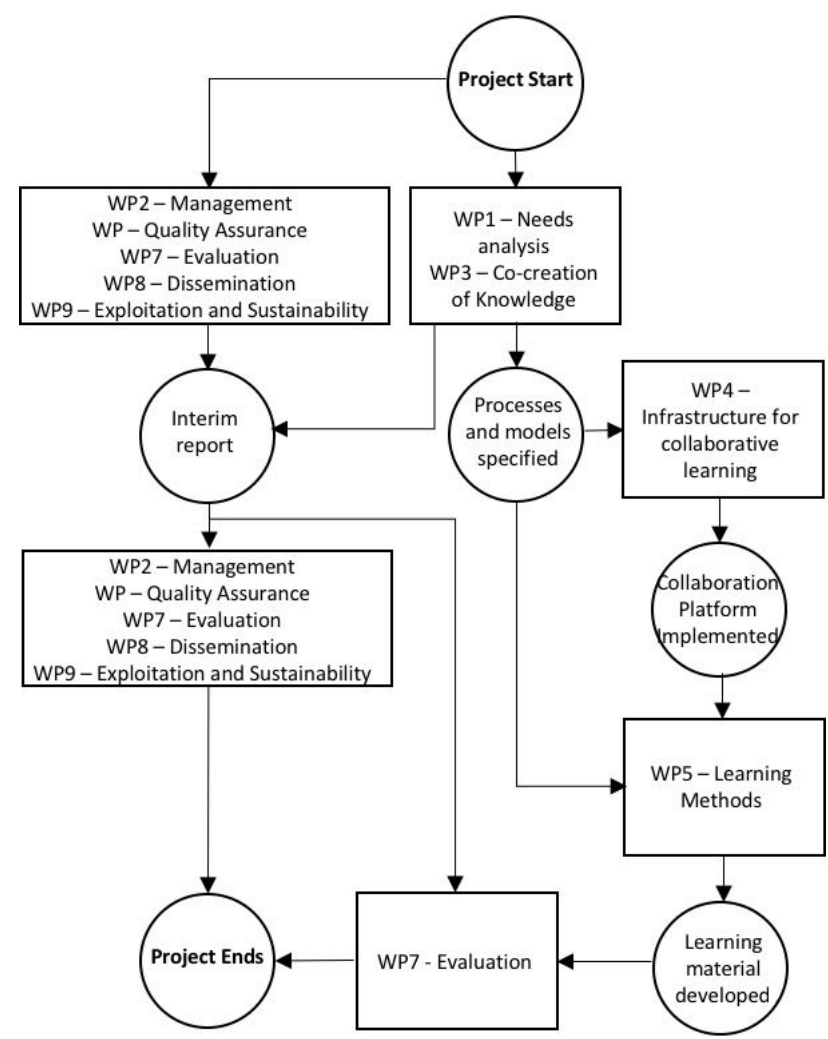

Figure 1. Representation of the giCASES methodology.

Project management plays a key role in the project covering, among others, the activities for quality assurance and quality evaluation. The quality and relevance of learning material and processes is evaluated using questionnaires during the testing phase, while the processes for co-creation and management of knowledge are assessed using targeted interviews to representatives of HEIs and businesses. From the quality assurance perspective, two sets of indicators were defined, i.e. results indicators, which ensure that the main processes of the project produce the planned outputs (meant as the tangible 
outputs of project activities, e.g. the deliverables); and impact indicators, which ensure to achieve the quality of project results and outcomes (meant as the intangible project effects, measured also beyond the project lifetime). A risk register was also set-up, aiming at identifying the project risks and supporting the implementation of a risk mitigation strategy.

The constant monitoring of results and impact indicators is also relevant, in the giCASES methodology, to ensure a fertile ground to exploitation activities. Exploitation can be defined as a planned process enabling: to transfer the successful results and outcomes of the project to appropriate beneficiaries and decision-makers; to convince individual end-users to adopt or apply the results and outcomes of the project; and to target enduser groups in order to multiply the adoption/application of the project results and outcomes within their communities. The giCASES exploitation strategy aims at answering the guiding questions represented in Figure 2, where:

- "What" refers to the project results and outcomes, whose quality must be constantly monitored and ensured;

- "How" refers to the 6 Exploitation Pillars (EPs) identified to support the exploitation of the giCASES results and outcomes (Martirano and Vercillo, 2017);

- "Who" is the giCASES Alliance, to be built as a network consisting of territorial and thematic nodes, representing altogether an accredited and recognized educational initiative to further exploit the university-business collaboration model developed within giCASES. The initial nodes are the project partners and other nodes are being established during and after the project lifetime.

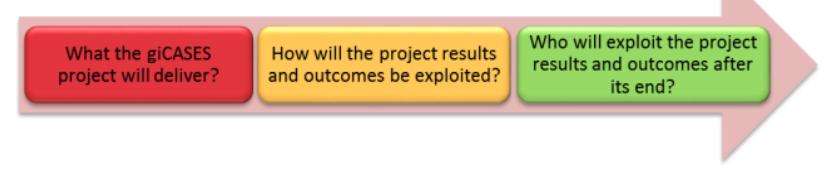

Figure 2. giCASES exploitation guiding questions (source: Martirano and Vercillo, 2017).

\subsection{Need analysis and state of art}

In order to better understand the current state of play with regard to case-based and collaborative learning, and the cocreation of knowledge in the geospatial education and training fields, a survey and a screening of existing (best) practices were organised. The objective of the survey was to contribute to a better understanding of how HEIs are currently working together with private companies and public administrations in Europe in the design and delivery of GI Science \& Technology (GIS\&T) education and training. The questionnaire was built around 6 main topics: 1) the characteristics of the responding organisation; 2) the types of collaboration currently in place between the academic and public/private partners; 3) the perceived benefits of education-related collaboration for the different involved parties, and the expected impact of this collaboration on realizing a better match between education and practice in particular; 4) the type of initiatives and actions undertaken to strengthen education-related collaboration; 5) the requirements for a collaborative learning platform; and 6) the knowledge assets and knowledge management strategies of the organisation. The questionnaire was sent through various channels including the networks of European and national associations active in the GIS\&T field such as EuroSDR, EuroGeographics, OSGeo, GeoForAll, AGI (UK) and FLAGIS (BE). In total, 150 respondents from the academic and public/ private sectors participated in the survey, of which 136 responses could be used for the analysis (incomplete or erroneous responses were removed).

The types of involvement of public and private sector organisations in the education-related activities of HEIs, as observed by the former, reflect a high degree of variability (see Table 1). The most common ways in which private and public organisations contribute to or participate in learning and teaching processes are through internships for students in their organisations. In addition, the provision of assets such as data and tools that can be re-used in teaching and learning and the participation in teaching activities through guest lectures are commonly used ways of collaboration with HEIs in GIS\&T education.

\begin{tabular}{|c|c|c|c|}
\hline Type of involvement & $\begin{array}{c}\text { No } \\
\text { involv. }\end{array}$ & $\begin{array}{c}\text { One time } \\
\text { involv. }\end{array}$ & $\begin{array}{l}\text { Long term } \\
\text { involv. }\end{array}$ \\
\hline $\begin{array}{l}\text { Teaching activities (e.g. } \\
\text { guest lectures) }\end{array}$ & $32.4 \%$ & $46.5 \%$ & $21.1 \%$ \\
\hline Internships & $22.5 \%$ & $52.1 \%$ & $25.4 \%$ \\
\hline $\begin{array}{l}\text { Input on topics for research } \\
\text { projects }\end{array}$ & $19.7 \%$ & $50.7 \%$ & $29.6 \%$ \\
\hline $\begin{array}{l}\text { Excursions/visits to private } \\
\text { or public organisations }\end{array}$ & $39.4 \%$ & $33.8 \%$ & $26.8 \%$ \\
\hline $\begin{array}{l}\text { Use of assets provided by } \\
\text { private/public organisations } \\
\text { (software, data, etc.) }\end{array}$ & $32.4 \%$ & $40.8 \%$ & $26.8 \%$ \\
\hline $\begin{array}{l}\text { Work on real-life business } \\
\text { cases }\end{array}$ & $38.0 \%$ & $45.1 \%$ & $16.9 \%$ \\
\hline $\begin{array}{l}\text { Participation of private or } \\
\text { public organisations in the } \\
\text { examination of students }\end{array}$ & $57.7 \%$ & $29.6 \%$ & $12.7 \%$ \\
\hline $\begin{array}{l}\text { Tutoring and/or mentoring } \\
\text { of students }\end{array}$ & $40.8 \%$ & $38.0 \%$ & $21.1 \%$ \\
\hline
\end{tabular}

Table 1. Involvement of private/public sector in educationrelated activities of HEIs as observed by private/public sector respondents (source: Vancauwenberghe and Vandenbroucke, 2016).

The major findings of the survey can be summarized as follows (Vancauwenberghe and Vandenbroucke, 2016):

- General awareness and recognition of case-based teaching and learning as an effective and valuable method for realizing collaboration between different stakeholders in GIS\&T education. Both HEIs and organisations from the private or public sector seem to be convinced of the added value of introducing case-based teaching and learning in GIS\&T education.

- Even if the idea of collaboration between HEIs and other stakeholders in designing and delivering GIS\&T education is not new, and most of the respondents in the survey already have some experience with education-related collaboration in the domain of GIS\&T, the collaboration between HEIs and other stakeholders in designing and delivering GIS\&T education is still organised in a rather 'traditional' manner. 
- The work on real-life case studies defined by private companies or public organisations is one of the most preferred types of collaboration. The participation of representatives from public or private organisations in teaching activities and the organisation of internships with actively involved students with clear responsibilities at private companies and/or public authorities are also preferred types of collaboration.

- Skills and competences in spatial data modelling, spatial data analysis, programming and application development and nontechnological disciplines have to be improved according to the market needs. The survey also highlighted the importance of developing and implementing collaborative approaches, including case-based approaches, in such a manner that benefits are delivered to all stakeholders, and not only to the students and the education institutions.

- A collaboration platform has to be open, easy-to-use, with integrated resources and tailored access to support the implementation of better collaboration between the students and private companies, which gives better opportunities for more case-based approaches in GIS\&T education. While HEI stakeholders primarily consider such a platform as a way to get access to data, tools and teaching material, the stakeholders from the private and public sectors consider the platform as an opportunity for interaction and collaboration with other stakeholders.

The survey was complemented with the identification, selection and documentation of a series of example (best) practices on case-based and collaborative learning, and the co-creation of knowledge. 15 best practice examples have been identified in an early stage of the project and documented in a repository of Best Practices (http://www.gicases.eu/best-practices).

\subsection{Processes and tools for co-creation of knowledge}

Based on the results of the survey and the repository of Best Practices (see Subsection 2.1) and in line with the preliminary organization of the CSs (see Section 3), a second task was the specification of the processes and tools required for co-creation of knowledge. This was done by describing the processes to be applied by the different actors involved in the case-based learning process (including students, professors, academic tutors and industry tutors) and in creating guidelines, templates and draft agreements to assist in the practical development of these processes.

The task revolved around the key concept of a 'use case', which refers to a high-level description of the collaborative processes, the related actors and their mutual interactions. In other words, use cases represent the abstraction required to model the processes of co-creation of knowledge (Minghini and Brovelli, 2017). A use case can be used to model the processes happening in multiple CSs, and a CS can be described by multiple use cases. Therefore, there is a $\mathrm{N}: \mathrm{M}$ relationship between the number of use cases and the number of case studies.

The processes of case-based learning and co-creation of knowledge may be classified in terms of degree of collaboration and type of output. According to the degree of collaboration, the processes may be classified as "autonomous" (there is no collaboration at all between the actors), "shared" (each actor performs his own tasks independently under a common agreement) and "collaborative" (all actors cooperate and contribute to the result). As the main objective of the project is to intensify collaboration between academia and industry, the first type of process is not considered. According to the type of output, the processes may be classified by looking at the main result(s) achieved: "learning material" and/or "training/ education".

The use cases (process patterns) were described through the Business Process Management Notation (BPMN; Object Management Group, 2011). The BPMN models were developed on top of the components introduced by Barchetti et al. (2011) to describe the collaborative processes occurring in the context of Enterprise 2.0 (McAfee, 2006). This term denotes the recent dimension entered by SME (Small Medium Enterprise) and characterized by the use of Web 2.0 (O'Reilly, 2005) and social networking facilities which enable functionalities such as communication, file/code sharing and development, knowledge networking, calendaring and scheduling. The main idea is that, by tracing and storing the huge amount of unstructured information generated from Web 2.0 tools, better knowledge management, efficiency and effectiveness can be achieved. More in detail, Barchetti et al. (2011) define a number of design patterns to model recurrent problems focused on managing the collaboration among actors that must complete a work without a predefined and pre-structured sequence of tasks: Collaborative Decision Making, Collaborative Editing, Collaborate and Aggregate activity loop. These patterns, which may be used in separate contexts or may be aggregated, are extremely beneficial to the giCASES approach and the 6 CSs.

Thus, following the previous classifications of the processes according to degree of collaboration and type of output, based on the preliminary organization of the CSs (see Section 3 ) and using the design patterns by Barchetti et al. (2011) as building blocks, 4 process patterns were identified (Minghini and Brovelli, 2017):

- Shared Development of Learning Material: co-creation of knowledge happens through the development of training material. All the aspects related to the development of training material are initially discussed and agreed between the academic and industry partners; then, the partners develop and share the material by working in parallel with a constant, mutual interaction.

- Collaborative Development of Learning Material: cocreation of knowledge happens through the development of training material. Again, the academic and industry partners initially discuss and agree on all aspects related to the training material to be developed. However, unlike the previous case, the partners develop the material by working collaboratively, which means either physically or using any tool offering collaboration functions.

- Shared Provision of Training: co-creation of knowledge happens through the provision of training to students. All the aspects related to the provision of training are initially discussed and agreed between the academic and industry partners. Then, the provision of training happens with the university and company staff working in parallel (i.e. each providing its own training) with a constant, mutual interaction. Provision of training can happen either in presence, i.e. with a physical presence at the university course or via an e-learning or distance learning course through an online medium. 
- Internship: co-creation of knowledge happens through the internship of one or multiple students. While all the aspects of the internship are discussed and agreed in advance by the academic and the industry staff, and training materials are prepared as well, during the internship the students interact and collaborate physically with the industry staff.

Each process pattern was described in detail using the BPMN. As an example, Figure 2 shows the BPMN diagram for the process Shared Development of Learning Material, which makes use of the sub-process Collaborative Decision Making by Barchetti et al. (2011) and the sub-process Parallel Development, which is also depicted in Figure 3.
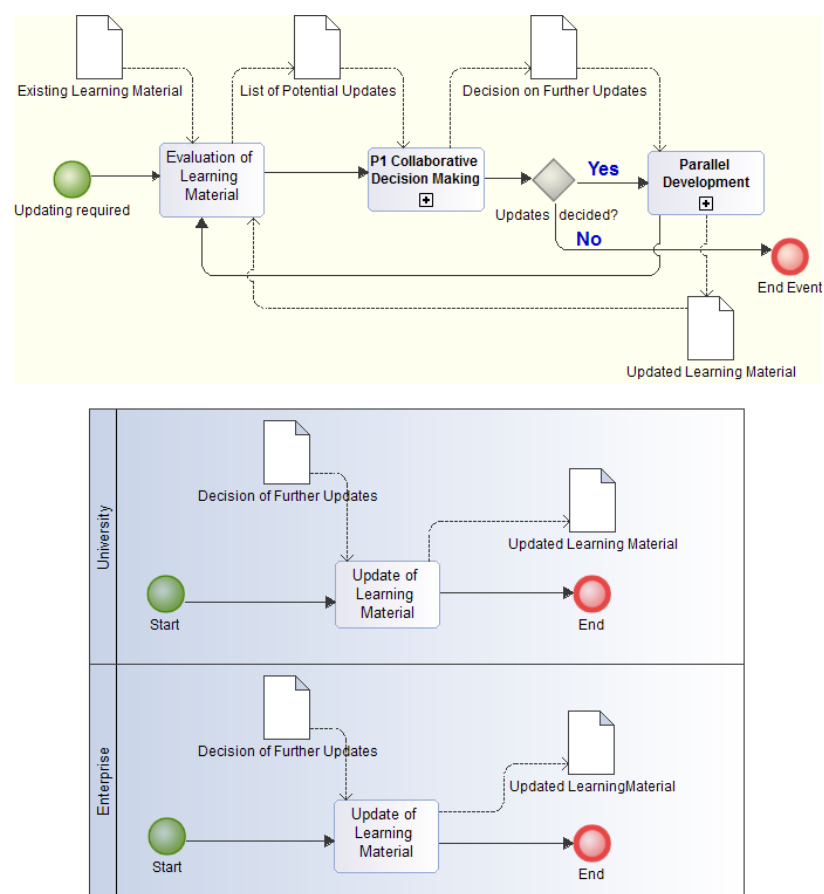

Figure 3. BPMN diagrams for the process Shared Development of Learning Material (top) and its sub-process Parallel

Development (bottom) (source: Minghini and Brovelli, 2017).

Following the specification of the process patterns described above, a number of draft agreements, templates and guidelines for the different stages of the work (i.e. the messages or data objects related to the activities specified in the BPMN models) were created to assist the actors involved in the implementation of each CS in the practical and context-specific development of the collaborative actions (Östman and Östman, 2017).

\subsection{Collaboration tools}

A key component for the CS implementation which is currently under study in the giCASES workflow consists of collaboration tools, which are mainly designed to make the cooperation between several actors more effective and transparent. In the context of the project, collaboration tools must ensure the practical accomplishment of the process patterns described above. Many of the tools available on the market provide builtin collaboration features, but it is more common for pure-play collaboration tools to be integrated with an already existing communication and workflow infrastructure of a company or project team. E-mail is still the most used form of communication, which however lacks important features that are essential for collaborative work in these fast-living times, where group chats, app integrations, voice and video calling are only a few examples of new opportunities in a collaborative environment.

The access to teaching and learning material and the interaction with other stakeholders represent key collaborative functionalities in giCASES. By its very nature the project is based on the concept of openness, addressed in the sense not only of tools and practices for free and open sharing of educational material, but also open accessibility, open licensing policy, freedom of place, pace and time of study. Thus, access to the collaborative platform should be open, contents of the platform should be accessible free of charge, (geospatial) data should be published either as open data or should at least not require to sign any licensing documents, tools should be open source, and lectures and course materials should also be published under an open access policy.

The degree of collaboration within the CSs may vary, depending on the specific conditions of each CS. In the simplest form, enterprises and universities will jointly develop learning material, such as test case descriptions in text form. The assets to be stored and shared are assumed to consist of descriptions (with links to proper theories), data for exercises, descriptions of exercises, normative solutions, self-tests and other appropriate learning material. In a slightly more advanced model, the learning material will be developed in multimedia format, indicating that it has to be used in interactive learning environments. In the most advanced collaboration form investigated, students, university staff and industry staff will jointly share the same work environment (sandbox) to solve real world problems. The latter would include the use of additional platforms and tools such as GitHub and Redmine, but also the preservation (in the cloud) of technical components co-created during the learning process such as web services, apps, etc.

The solutions developed, extended or integrated within giCASES will take into account state-of-the-art technologies and methodologies in distance learning, knowledge sharing and collaborative work. The project will have preference for open source Learning Management Systems (LMS) and open source solutions in collaborative software, community building software, web conferencing and networking software.

\section{CASE STUDIES}

As mentioned above, the CSs are the means by which the processes of co-creation of knowledge, once identified and described (see Subsection 2.2), are exemplified and tested in practice. A set of 6 real-world problems in the GI domain were identified, each of which is further developed in a collaborative way in a case-based learning environment by one university and one industrial partner of the giCASES consortium. The $6 \mathrm{CSs}$, whose implementation is scheduled during the second half of the project duration (from mid-2017 to the end of 2018), are the following:

1) Use of indoor GIS in healthcare: this CS explores the new research and innovation challenge of indoor Location Based Services (LBS), which is key for business activities in several scenarios such as e-government services, eHealth, personal mobility, logistics, facility management and retail. The objective is to introduce students (both theoretically and practically) to the topic of GIS-based indoor LBS and engage them in the development of a real application exploiting a Wi-Fi based 
indoor localisation system that tracks and visualizes the movement of devices or people.

2) Environmental analysis using a cloud service system: this CS aims to apply the scientific knowledge given by research activities to a more practical assessment of potential environmental hazards that could be useful to both public authorities and environmental consultants. A new professional set of skills and expertise will be created to integrate the GIS competences of analyst staff (at universities) using a webGIS tool as well as to improve the capacity of the environmental expert (usually in public authorities such as environmental agencies) to set-up data and perform analysis in a new type of platform, contributing to the improvement of hazard analysis. The CS also represents a good example of integration of assessment of spatial data by open source and webGIS applications and environmental information.

3) Location enablement of e-government: this CS investigates the uptake and integration of location information and web services in e-governmental business processes such as the request for a building permit using SDI components and APIs. The work will be developed in the form of an internship, where students will work with staff from the company to design, develop and/or test geospatial web applications. In addition to consolidating theoretical knowledge and technical skills in GI and GIS development and usage, students will gain experience in designing and developing applications for making spatial data available, for decision making and e-government, with particular focus on Scrum methods in the form of sprints to design, develop and test code that will be managed on collaborative development platforms such as GitHub.

4) Integrated management of the underground: this CS explores the role of GIS technology in the management of utility networks in different sectors (water, electricity, sewage, stormwater, fiber optics, cable-TV and telecommunication). The goal is to make students acquainted with problems related to the asset management of utility networks and the sharing of utility network data. Besides acquiring knowledge about domainrelated concepts and terms, students will learn to publish utility network data through standardised network services, specify different requirements on asset management system for utility network, and understand the complexity, objectives and benefits of modern GIS software for management of utility network.

5) Harmonizing data flows in energy saving EU policies: this CS addresses the topic of GIS-based data flows in energy efficiency EU policies and relies on the concepts, principles and technicalities of the EU INSPIRE Directive to increase data interoperability. After analysing the relevant EU policies related to energy efficiency, students will be involved in a practical workflow based on identifying a relevant business process contained in one of the policies; identifying data, methodologies and tools required to run the business process; analysing input data availability and accessibility; applying the methodologies to obtain output data; and presenting the results. The workflow will be tested in a real case at local level.

6) GIS Applications in forestry: this CS concerns the use of GIS technology for forest planning and management. This is a rather complex topic, as it is characterized by multiple objectives to fulfil as well as multiple and demanding criteria and constraints to address. The CS will feature a mix of theoretical lectures and practical sessions to provide students both with the theoretical background and real-case experience about GIS applications in forestry. Students will not just acquire technical skills on how to apply spatial analysis techniques, prepare thematic maps for decision makers, etc., but they will also develop a critical awareness of forest management-related issues such as forest fire events.

Each CS has a well-defined scope, learning outcomes, results, time frames, actors and corresponding roles (Giori et al., 2016). Nevertheless, co-creation of knowledge in all the CSs will allow students to exercise social skills, develop attitudes such as flexibility, coping with stress, ability to organize, to be critical and to be geared towards results. It is also interesting to note that, despite the use of open source software (and specifically FOSS4G) was not a formal requirement of the project, all the 6 CSs will make extensive use of such technologies: among others, QGIS, GRASS GIS, PostGIS, GeoServer, Geomajas, OpenLayers, and Leaflet. This shows how open source solutions are widely used not just as GI teaching tools at the universities, but also as a powerful means to develop innovative products/services at the companies in a diversity of application domains. Exploitation of open geospatial data and open GI standards from the Open Geospatial Consortium (OGC) will be key as well in the CSs

\section{CONCLUSIONS}

The GI sector is high-pace evolving as a consequence of the convergence of many different technological and social aspects, from the availability of hyper-connected localisation sensors and high-resolution imagery to new emerging paradigms such as data interoperability, (linked) open data and citizen science. A commitment for HEIs to continuously update their curricula in order to respond to these changing societal needs is fundamental.

giCASES aims primarily at structuring and innovating the collaboration between industrial players and HEIs to ensure that curricula in the GI education field take into account the new technological requirements. The close collaboration patterns introduced by the project are envisaged as a significant innovation compared to the rather traditional forms of cooperation between HEIs and the public/private sector. The purpose of giCASES is to boost the innovation at universities and enterprises by developing and implementing new GI teaching and learning methods based on "openness". Here this concept applies not only to tools, software and materials, but also to accessibility, licensing policy, freedom of place, pace and time of study. The project is largely based on open source LMS and open source solutions in collaborative software, community building software, web conferencing and networking software. Therefore, the outcomes will be relevant on one side to GeoForAll and the whole FOSS4G Education Community and, on the other side, to the many SMEs active in the GI sector, which are looking at the new technological trends (addressed by giCASES) as a great business opportunity to create new innovative products/services and/or innovate the existing ones. In this perspective, a key challenge of the project is to find a good mechanism to separate the shared know-how from the protected Intellectual Property Rights (IPR) needed for the industries to do business.

At the current status the methodology for co-creation of knowledge, i.e. the theoretical approach of giCASES, has been completely defined, while the applied collaboration tools and the CSs, where the theoretical approach will be crystallised and tested in practice, are being studied and deepened. The findings 
achieved so far, despite being only partial results of the project, are however interesting and promising. The challenge addressed by giCASES is indeed ambitious, since the developed approach and methodology for university-business cooperation is expected to have, in the medium and long term, a concrete impact on the institutional settings at the academic level. The intention is in fact to involve businesses in the definition of learning paths since the very beginning, i.e. at the design stage, to boost people employability through the acquisition of competences (skills, theoretical knowledge and attitudes) facing current real-market requirements. As it was noticed earlier that FOSS4G is heavily used in the different CSs, it is important to work on capacity building based on these solutions, as they will improve co-creation and collaboration in the future.

Since the learning offer should respond to market needs timely, it is no longer possible to develop curricula or, in general, learning paths, either in formal or informal settings, based on identified needs, since those needs will have changed in the same timespan needed by HEIs to design and put in place the curricula. That is why the involvement of businesses in instructional design must become the standard way to match labour market needs, and the case-based approach proposed by giCASES, together with the collaborative learning paradigm to foster co-creation of knowledge, are considered as the elective tools to achieve such an ambitious scope.

This collaboration model, when widely adopted, will also address the acquisition of transversal and soft skills, which are nowadays recognised as labour market-relevant skills to boost employability and competitiveness of the workforce, in line with the communication by the European Commission "A new skills agenda for Europe" (European Commission, 2016). Thanks to the open access policy adopted by giCASES and the replicability of the developed methodology, other stakeholders are expected to join the Alliance and to adopt its case-based approach as a university-business cooperation model, generating a direct or indirect effect on actors, structures, sectors or systems at the EU level.

\section{ACKNOWLEDGEMENTS}

This work was supported by the project "giCASES - Creating a University-Enterprise Alliance for a Spatially Enabled Society", co-funded by the Erasmus+ Programme of the European Union, Knowledge Alliances $N^{\circ}$ 562657-EPP-A-2015-1-IT-EPPKA2KA.

\section{REFERENCES}

Barchetti, U., Capodieci, A., Guido, A. L., Mainetti, L., 2011. Modelling collaboration processes through design patterns. Computing and Informatics, 30(1), pp. 113-135.

Bukowitz, W. R., Williams, R. L., 1999. The knowledge management field book. FT Management, London.

European Commission, 2007. Key Competences for lifelong learning - A European Reference Framework. Office for Official Publications of the European Communities, Luxembourg.

European Commission, 2008. The European Qualifications Framework for Lifelong Learning (EQF). Office for Official Publications of the European Communities, Luxembourg.
European Commission, 2016. A New Skills Agenda for Europe. Office for Official Publications of the European Communities, Luxembourg.

Giori, A., Baptista, A., Östman, A., Vecchio, A., Cipolloni, C., Czimber, K., Vandenbroucke, D., Krikigianni, E., Pascarella, F., Martirano, G., Saio, G., Facchin, I., Bonazountas, M., Minghini, M., Painho, M., Brovelli, M. A., Bela, M., Carbonaro, M., Calace, N., Molina, R., Moreira de Oliveira, T., Tsiakos, V., 2016. Definition of the focus, scope and requirements of the case studies - Deliverable no. D.1.3.

Martirano, G., Vercillo, A., 2017. Exploitation Plan 1 Deliverable no. D.9.1. http://www.gicases.eu/publications (26 May 2017).

McAfee, A. P., 2006. Enterprise 2.0: The dawn of emergent collaboration. MIT Sloan management review, 47(3), 21.

Minghini, M., Brovelli, M. A., 2017. Process and tools for cocreation of knowledge - Deliverable no. D.3.1. http://www.gicases.eu/publications (26 May 2017).

Object Management Group, 2011. Documents Associated with Business Process Model and Notation ${ }^{\mathrm{TM}}$ (BPMNTM) Version 2.0. http://www.omg.org/spec/BPMN/2.0 (26 May 2017).

Östman, A., Östman, M., 2017. Specification of methodology for co-creation of knowledge - Deliverable no. D.3.2.

O'Reilly, T., 2005. What is Web 2.0: Design patterns and business models for the next generation of software. http://oreilly.com/pub/a/web2/archive/what-is-web-20.html (26 May 2017).

Rip, F., Wallentin, G., van Lammeren, R., 2014. Integrated analysis of the demand for and supply of geospatial education and training - Results of the GI-N2K Surveys. http://www.gin2k.eu/?wpdmdl=452 (26 May 2017).

Vancauwenberghe, G., Vandenbroucke, D. 2016. Collaborative learning: Analysis of the needs of industry and academia Deliverable no. D.1.1. http://www.gicases.eu/publications (26 May 2017).

Vandenbroucke, D., Vancauwenberghe, G., Crompvoets, J., Pignatelli, F., Smits, P., Boguslawski, R., Vowles, G., Borzacchiello, M. T., 2014. Assessment of the Conditions for a European Union Location Framework (EULF). JRC, Ispra. https://ec.europa.eu/isa2/sites/isa/files/assessment-of-theconditions-for-an-eulf-v1_en.pdf (26 May 2017).

Wikipedia, $2017 . \quad$ Richard Stallman. https://en.wikipedia.org/wiki/Richard_Stallman (26 May 2017). 